\title{
Simulations of Kerr based non linear optical components with the Complex Jacobi iteration
}

\author{
Peter Vandersteegen, Peter Bienstman, Roel Baets \\ Department of information technology, UGent-IMEC, St Pietersnieuwsstraat 41, B-9000 Ghent, \\ Peter.Vandersteegen@intec.UGent.be
}

Adrien Dewandre, Marc Haelterman

Faculté des Sciences Appliquées, Service de Physique Générale, ULB, CP165/81, avenue F.D. Roosevelt 50, B-1050 Bruxelles

We present several non-linear structures simulated with the non-linear complex Jacobi iteration. This method numerically integrates the fields of the Helmholtz equation for points located on a grid. Because the fields are calculated on each grid point this results in a very flexible method. This iterative method refines each iteration step the calculated fields until a desired error has been achieved.

The first structure under discussion is a one dimensional study of a cavity surrounded by two Bragg gratings, fig. 1(a). These two Bragg gratings create a photonic band gap. The introduced cavity creates a resonance wavelength in the middle of this band gap. All light with this resonance wavelength will be transmitted by this structure. Introducing a non-linear material in the cavity will shift the resonance peak to higher wavelengths. A comparison with non-linear eigenmode expansion confirms the accuracy of our simulation tool. We have also shown that the numerical dispersion introduced by a discrete mesh can be controlled if the discretization step $\Delta x<\frac{\lambda}{20}$.

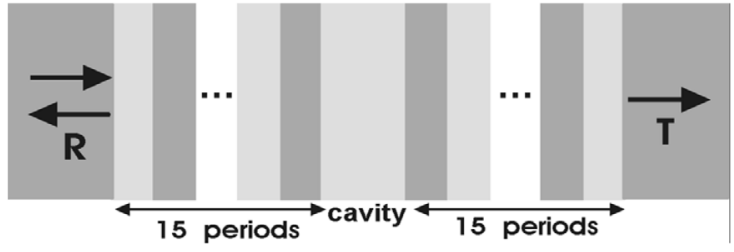

(a) Cavity encapsulated by 2 Bragg gratings

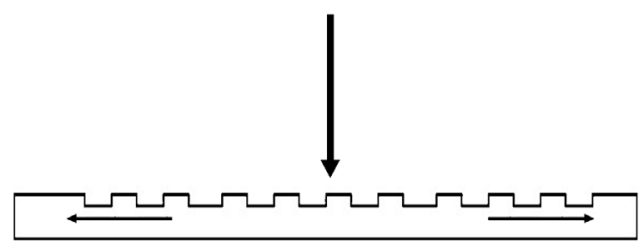

(b) Vertical grating coupler

Fig. 1. Non linear wavelength scale structures

We will also present preliminary simulation results from a 2 dimensional vertical coupler. Light coupled vertically in the coupler is symmetrically injected in a left and right waveguide. Injection efficiency in one waveguide reaches a maximum for a certain wavelength. Adding non-linearity in the grating material will hopefully result in a shift of this maximum.

Parts of this work has been performed in the context of the Belgian IAP Photon network.

[1] G. Ronald Hadley, 'Solving the 3D Helmholtz Equation By Complex Jacobi Iteration', Optical Waveguide Theory and Numerical Modelling 2004, OWTNM'04, p.15, 2004.

[2] Peter Vandersteegen, Peter Bienstman and Roel Bates, 'Using the Complex Jacobi method to simulate Kerr non-linear photonic components', Optical and Quantum Electronics (to be published) 


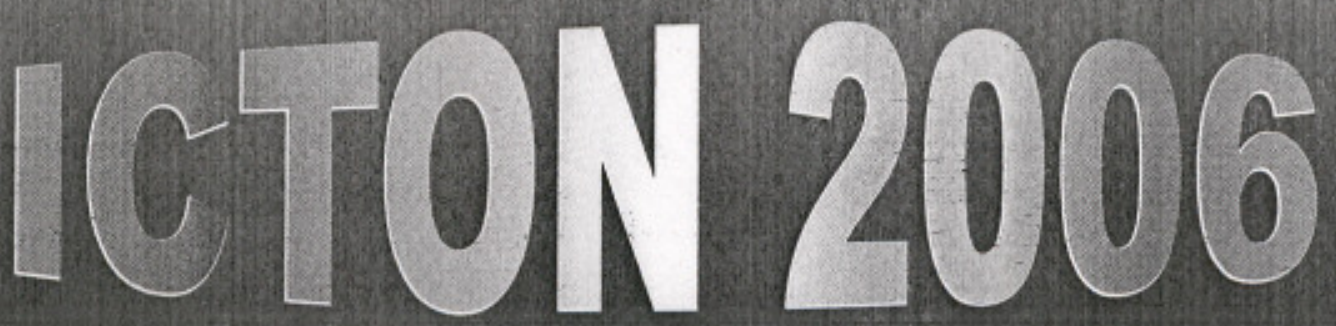

\title{
$8^{\text {th }}$ International Conference
}

on

\section{Transparent Optical Networks}

co-located with:

\begin{abstract}
ESPC $\quad 5^{\text {n }}$ European Symposium on Photonic Crystals
WAOR $\quad 5^{\text {n }}$ Workshop on All-Optical Routing

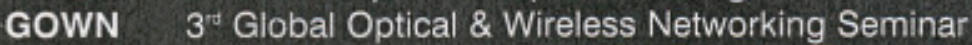

RONEXT $2^{\text {r }}$ COST 270 Workshop on Reliability Issues in Next Generation Optical Networks

PICAW $\quad 2^{\text {rd }}$ Photonic Integrated Components \& Applications Workshop

NAON COST 288 Nanophotonics for All-Optical Networking Workshop

GRAAL COST 293 Annual Conference on Graphs and Algorithms in Communication Networks

COST P11 Training School: Modelling and Simulation Tecinniques for Linear, Nonlinear and Active

Photonic Crystals

\section{and special sessions:}

MPM - Microresonators and Photonic Molecules: trapping, harnessing and releasing light Industrial
\end{abstract}

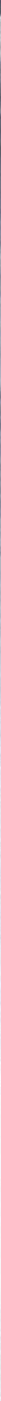


Editor: Marian Marciniak

Associate Editor: Marek Jaworski

Technical Editors: Marcin Chochot, Mariusz Zdanowicz

Cover photos by Hanna Skrobek.

front - panoramic view of the University park campus with Trent building

back - Nottingham castle wall with Robin Hood statue

Printed by National Institute of Telecommunications, Transmission and Fiber Optics Department

Copyright and Reprint Permission: Abstracting is permitted with credit to the source. Libraries are permitted to photocopy beyond the limit of U.S. copyright law for private use of patrons those articles in this volume that carry a code at the bottom of the first page, provided the per-copy fee indicated in the code is paid through Copyright Clearance Center, 222 Rosewood Drive, Danvers, MA 01923. For other copying, reprint or republication permission, write to IEEE Copyrights Manager, IEEE Operations Center, 445 Hoes Lane, P.O. Box 1331, Piscataway, NJ 088551331. All rights reserved. Copyright $\odot 2006$ by the Institute of Electrical and Electronics Engineers, Inc.

IEEE Catalog Number: 06EX1326

ISBN: 1-4244-0235-2

Library of Congress: 2006921097 